\title{
Synthesis, Characterization and Thermal Behavior of Novel Acrylate Polymers Based on N- (benzothiazole-2-yl) Maleimide
}

\author{
F. Abdel Hai, H. Abdel Wahab, A. Galal* and H. S. Nassar \\ Department of Applied Chemistry, Faculty of Science, Al-Azhar \\ University, Cairo, Egypt.
}

\begin{abstract}
T $\mathrm{N}$ the present study novel acrylate polymers were prepared from different feed compositions of ethyl acrylate (EA), methyl methacrylate (MMA), styrene (St) and N-(benzothiazole-2-yl) maleimide (BTM) monomer via emulsion polymerization technique using sodium lauryl sulfate as a surfactant and ammonium persulfate as an initiator. The chemical structure of BTM monomer was confirmed by elemental analysis in addition to FT-IR, ${ }^{1} \mathrm{H}-\mathrm{NMR}$ and mass spectroscopy. The prepared acrylate polymers of different compositions were also investigated by FT-IR, GPC, TGA and DSC. The solubility of both BTM monomer and the formed polymers of different compositions in various solvents was also investigated. The obtained results showed that the thermal decomposition of the prepared polymers which has taken place occurred in a single step in the temperature range from 345 to $436^{\circ} \mathrm{C}$. The mechanism of the thermal degradation of the prepared polymers was confirmed via kinetic analysis of their thermal degradation using Broido, CoatsRedfern and Horowitz-Metzger methods.
\end{abstract}

Keywords: Acrylate polymer, N-(benzothiazole-2-yl) maleimide, Thermal gravimetric analysis and Kinetic analysis.

In the recent years some comprehensive work has been published on the synthesis of new types of plastic materials by modification of commodity polymers in order to improve their properties to meet requirements for new applications. One of the existing methods of improving polymer properties is the copolymerization. Polymers of $\mathrm{N}$-substituted maleimides and their derivatives can be classified as polyimides, important high performance engineering plastics, being a class of rigid polymers because of the imide rings in the backbone. This provides the polymers with superior mechanical and thermal stability. The peculiar homo- and copolymerization characteristics of the maleimide group make it an attractive monomer for designing special vinyl polymers. Although maleimide undergoes homopolymerization with great difficulty, it copolymerizes

*Corresponding author. Tel.: (02) 01115492817; E-mail: ahmed_20201422@yahoo.com 
quite readily with a variety of vinyl monomers. Apart from enhancing the thermal stability and glass transition temperature of the resultant copolymers, the maleimide group can effectively serve as a vehicle for many functional groups for their predefined distribution in a vinyl polymer backbone through free radical copolymerization. One of the main advantages offered by functional maleimides, is the fact that new monomers with desired substituents to the imino nitrogen can be readily prepared. Free radical polymerization and copolymerization of $\mathrm{N}$ substituted maleimides, with various vinyl monomers, have been reported in a number of papers ${ }^{(1-3)}$.

The utilization of thermo gravimetric analysis (TGA), to study the thermal stability and degradation behavior of the polymeric systems, has attracted much attention. Many reports were carried out in this field ${ }^{(4-7)}$. Hanzhou Liu et al . introduced acrylonitrile onto poly ethylene nonwoven fabric via a pre-irradiation induced emulsion graft polymerization method. The thermal stability of the grafted polymer is measured by thermo gravimetric analysis (TGA) ${ }^{(8)}$. Sinem Kadriye Cekingen et al. synthesized a novel 2-\{[2-(3-thienyl) acetyl]oxy $\}$ ethyl 2methylacrylate (HEMAT) monomer. Polymer and random copolymer of HEMAT and methyl methacrylate (MMA) were prepared. Thermal behavior of HEMAT polymer and copolymer with MMA was also investigated by thermo gravimetric analysis (TGA). The apparent activation energies for thermal degradation were obtained by Kissinger and Tang methods ${ }^{\left({ }^{9}\right)}$. The present work focused on synthesis, characterization and thermal stability behavior of the novel acrylate polymers based on a new monomer containing benzothiazol ring. Degradation kinetic parameters such as energy of activation (Ea) for the prepared polymers were calculated using three mathematical models namely; Broido's $(\mathrm{BR})^{(10)}$, Coats-Redfern $(\mathrm{C}-\mathrm{R})^{(11)}$ and Horowitz-Metzger $(\mathrm{H}-\mathrm{M})^{(12)}$ for comparison purposes.

\section{Experimental}

\section{Materials}

The maleic anhydride, 2-aminobenzothaizole, anhydrous sodium acetate, acetic acid and poly vinyl alcohol (PVA) used were produced by Sigma-Aldrich Company Ltd based in UK. The ethyl acrylate (EA), methyl methacrylate (MMA) and styrene (St) used were produced by EIF chem. (ATCO) company in France. Sodium lauryl sulfate (SLS), ammonium persulfate and other chemicals were all supplied by the El-Naser Pharmaceutical Chemical Company in Egypt. Deionised water was used throughout the work.

\section{Synthesis of $\mathrm{N}$-(benzothiazole-2-yl) maleimide (BTM) monomer}

A mixture of maleic anhydride $(0.1$ mole, $9.8 \mathrm{~g})$, 2-amino-benzothaizole $(0.1$ mole, $15 \mathrm{~g})$ and anhydrous sodium acetate $(0.5 \mathrm{~g})$ in acetic acid $(200 \mathrm{ml})$ was refluxed for $6 \mathrm{hr}$. Then the resulting solution was poured into a crushed ice water mixture, where a yellowish white colored monomer was separated out. The solid obtained was filtered and washed several times with cold water and then dried. Further the monomer was recrystallized from an ethanol/benzene mixture. The Egypt. J. Chem. 56, No.4 (2013) 
reaction yield was then determined, as well as the physicochemical characteristics such as colour and melting point.

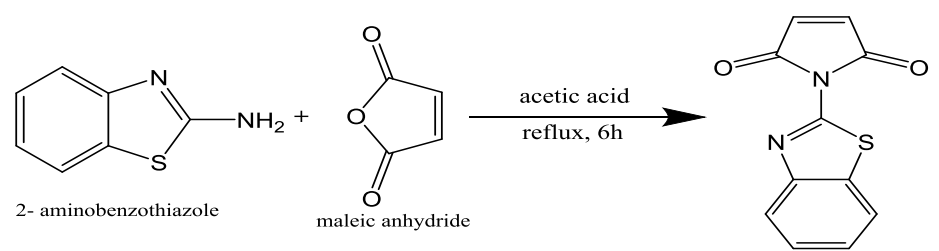

Scheme1. Synthesis of N-(benzothiazole-2-yl) maleimide (BTM) monomer.

Synthesis of the acrylate polymers based on N-(benzothiazole-2-yl) maleimide (BTM)

Ethyl acrylate $(24 \mathrm{~g})$, methyl methacrylate $(1 \mathrm{~g})$, styrene (variable), $\mathrm{N}$ (benzothiazole-2-yl) maleimide (BTM) (variable) and sodium lauryl sulfate emulsifier (SLS, $0.8 \mathrm{~g}$ ) were dispersed in $30 \mathrm{~g}$ of $1 \%$ PVA solution (0.3 $\mathrm{g}$ PVA in $29.7 \mathrm{~g}$ deionized water) to get a pre-emulsion by fast agitation. Then, $10 \%$ of the pre-emulsion, $15 \mathrm{~g}$ of $1 \%$ PVA solution, $0.5 \mathrm{~g}$ ammonium hydroxide (25\%) and $20 \%$ of the ammonium persulfate initiator weight $(0.096 \mathrm{~g})$ were added to a $500 \mathrm{ml}$ five-necked round-bottom flask fitted with a reflux condenser, a thermometer, a magnetic stirring bar and two separate feed streams, and the agitation was maintained at $200 \mathrm{rpm}$. Initially, the reaction flask was purged with nitrogen for $15 \mathrm{~min}$ and immersed in a water bath. When the temperature was raised to $80^{\circ} \mathrm{C}$ the remaining pre-emulsion, and the solution of the remaining initiator $(0.384 \mathrm{~g}$ in $5.22 \mathrm{~g}$ deionized water), were added to the flask over a 3 hour period. When the addition was complete, the reaction was kept at $80^{\circ} \mathrm{C}$ for a further $2 \mathrm{hr}$, to ensure complete monomer conversion, and then cooled. Part of the emulsion was diluted with water and the polymers were precipitated into excess acetone and extracted from ethanol for $12 \mathrm{hr}$ to remove all traces of water, surfactant and unreacted monomer residue. They were then dried under reduced pressure at room temperature for $24 \mathrm{hr}$.

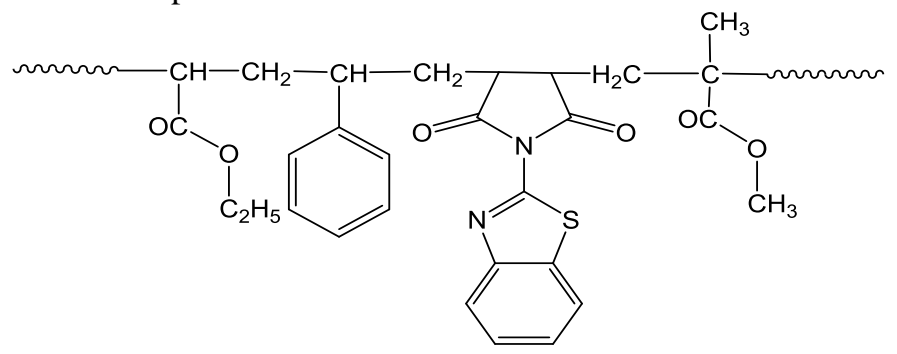

Scheme 2. Chemical structure of acrylate polymer containing thiazole moiety.

\section{Characterization techniques}

The elemental analysis for the synthesized N-(benzothiazole-2-yl) maleimide (BTM) monomer was undertaken at the National Research Center, Micro Analytical Centre, Giza, Egypt. The FT-IR spectra of the synthesized N- 
(benzothiazole-2-yl) maleimide (BTM) monomer and new acrylate polymers were recorded on a Nicolet 400D FT-IR spectrometer, using $\mathrm{KBr}$ pellets. The Mass spectra and the ${ }^{1} \mathrm{H}-\mathrm{NMR}$ spectra of the synthesized N-(benzothiazole-2-yl) maleimide (BTM) monomer were recorded on a Shimadzu QP-2010 (Tokyo, Japan) using the electron ionization mode and a Varian Mercury VX-300 NMR (Tokyo, Japan) spectrometer $(\delta, \mathrm{ppm})$ in DMSO-d6 at (300) $\mathrm{MHz}$, respectively. Thermal properties were examined using a simultaneous DSC-TGA (USA) Q600-SDT System from TA Instruments. The temperature range covered was $25-600{ }^{\circ} \mathrm{C}$ and the scanning rate $10^{\circ} \mathrm{C} \mathrm{min}^{-1}$, under nitrogen atmosphere. The molecular weight of the copolymers was obtained using WATERS 410-gel permeation chromatography equipped, fitted with a differential refractive index detector. Tetrahydrofuran was used as the eluent and polystyrene standards were employed for the calibration.

Solid content and monomer conversion (\%)

Total solid content (TSC) and monomer conversion (MC) were determined by a gravimetric analysis method using Equations 1 and 2, respectively.

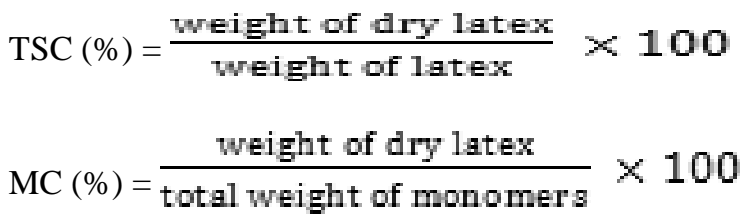

\section{Solubility studies}

Solubility of the synthesized N-(benzothiazole-2-yl) maleimide (BTM) monomer and the synthesized acrylate polymers were tested in various polar and non-polar solvents. About 5-10 mg of the sample was added to about $2 \mathrm{ml}$ of the respective solvent in a test tube and kept overnight with the tube tightly closed. The solubility of the polymers was noted after $24 \mathrm{hr}^{(13)}$.

\section{Results and Discussion}

Synthesis and characterization of $N$-(benzothiazole-2-yl) maleimide (BTM) monomer

In the present study, $\mathrm{N}$-(benzothiazole-2-yl) maleimide (BTM) monomer was prepared by refluxing maleic anhydride with 2 - aminobenzothiazole in an acetic acid/ anhydrous sodium acetate mixture as described in the experimental section. The chemical structure of the obtained BTM monomer is represented in Scheme 1. Elemental analysis, reaction yield and physical properties, such as melting point and product color, were measured and listed in Table 1. The good agreement between the experimental and theoretical values of the $\mathrm{C}, \mathrm{H}$ and $\mathrm{N}$ levels reveals that the methods of synthesis and purification of the product were performed successfully.

Egypt. J. Chem. 56, No.4 (2013) 
TABLE 1. Physico- chemical properties of N-(benzothiazole-2-yl) maleimide (BTM) monomer.

\begin{tabular}{|c|c|c|c|c|c|c|c|c|c|}
\hline \multicolumn{6}{|c|}{ Elemental analysis } & \multirow{3}{*}{$\underset{{ }^{\mathbf{m}} \cdot \mathbf{C}}{\mathbf{C}}$} & \multirow{3}{*}{$\begin{array}{c}\text { Mol. } \\
\text { Formula }\end{array}$} & \multirow{3}{*}{$\begin{array}{c}\text { Yield } \\
\%\end{array}$} & \multirow{3}{*}{ Color } \\
\hline \multicolumn{2}{|c|}{$\% \mathrm{C}$} & \multicolumn{2}{|c|}{$\% \mathrm{H}$} & \multicolumn{2}{|c|}{$\% \mathrm{~N}$} & & & & \\
\hline found & Calc. & found & Calc. & found & Calc. & & & & \\
\hline 57.67 & 57.38 & 2.67 & 2.63 & 12.33 & 12.17 & 160 & $\mathrm{C}_{11} \mathrm{H}_{6} \mathrm{~N}_{2} \mathrm{O}_{2} \mathrm{~S}$ & 88 & $\begin{array}{l}\text { Yellowish } \\
\text { white }\end{array}$ \\
\hline
\end{tabular}

Spectral analysis of $N$-(benzothiazole-2-yl) maleimide (BTM) monomer

Structural features of the synthesized $\mathrm{N}_{-}$(benzothiazole-2-yl) maleimide (BTM) monomer were confirmed using FT-IR, H-NMR and mass spectroscopy, as shown from Fig. 1, 2 and 3, respectively. This combination of techniques was utilized for structure confirmation. The key characteristic peaks of the FT-IR spectrum of the BTM monomer are as follows: $\left(\mathrm{KBr}, \mathrm{cm}^{-1}\right)$ functional groups observed [3052 (aromatic C-H), 2930 (aliphatic $\mathrm{C}-\mathrm{H}), 1712(\mathrm{C}=\mathrm{O}), 1602(\mathrm{C}=\mathrm{N})$, 1545, 1505 (aromatic ring), $1448(\mathrm{C}-\mathrm{N}), 1272(\mathrm{C}-\mathrm{S})$ and 755 (maleimide moiety)] are all typical for $\mathrm{N}$-(benzothiazole-2-yl) maleimide (BTM) monomer. The H-NMR spectrum was measured in DMSO-d6 solvent and showed peaks (ppm) at $\delta=7.82(\mathrm{~d}, 2 \mathrm{H}, \mathrm{CH}=\mathrm{CH}), 7.97-8.02(\mathrm{~d}, 2 \mathrm{H}, \mathrm{Ar} \mathrm{C}-\mathrm{H}$ adjacent to thiazole ring), 7- $7.75(\mathrm{~m}, 4 \mathrm{H}, \mathrm{ArH})$. The calculated mass spectra $(\mathrm{m} / \mathrm{z})$ for a BTM monomer of chemical for 2 mula $\mathrm{C}_{11} \mathrm{H}_{6} \mathrm{~N}_{2} \mathrm{O}_{2} \mathrm{~S}$ using the electron ionization mode was found to be 230, which reveals that the methods of synthesis and purification of the products were performed successfully.

Solubility studies of $N$-(benzothiazole-2-yl) maleimide (BTM) monomer

The N-(benzothiazole-2-yl) maleimide (BTM) monomer was found to be soluble in ethyl acetate, acetone, dioxane, tetrahydrofuran (THF), Dimethylsulfoxide (DMSO), Dimethylformamide (DMF), methylene chloride, chloroform, diethylether (sparingly) and also in alcohols such as methanol, ethanol and isopropanol. However, it was not soluble in distilled water, petroleum ether and hydrocarbon (e.g., n-hexane, benzene, toluene and xylene).

Synthesis and characterization of new acrylate copolymers based on $\mathrm{N}$ (benzothiazole-2-yl) maleimide (BTM)

In the present study new acrylate polymers of different feed compositions were prepared by means of emulsion polymerization in water, using sodium lauryl sulfate as a surfactant and ammonium persulfate as a water-soluble radical initiator, as described in the experimental section. The generalized chemical structure of the produced polymer is represented in Scheme 2 and the recipe and weight changes for the various polymer compositions are illustrated in Table 2. The amount of BTM used in the polymerization was 0, 1, 2, 3, 4 wt $\%$, corresponding to $\mathrm{E}_{\mathrm{o}}, \mathrm{E}_{1}, \mathrm{E}_{2}, \mathrm{E}_{3}$ and $\mathrm{E}_{4}$, respectively. 


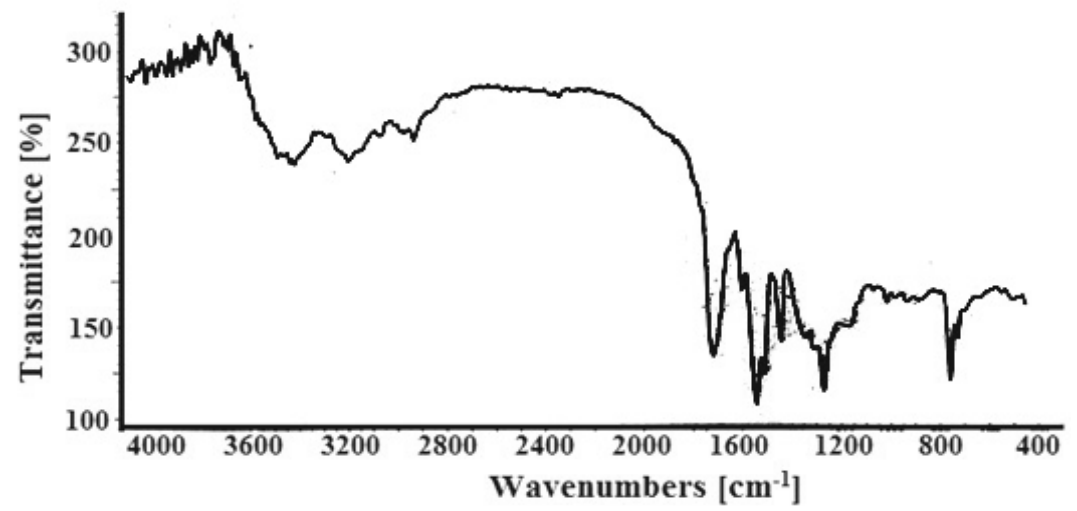

Fig. 1. IR spectra of N-(benzothiazole-2-yl) maleimide (BTM) monomer.

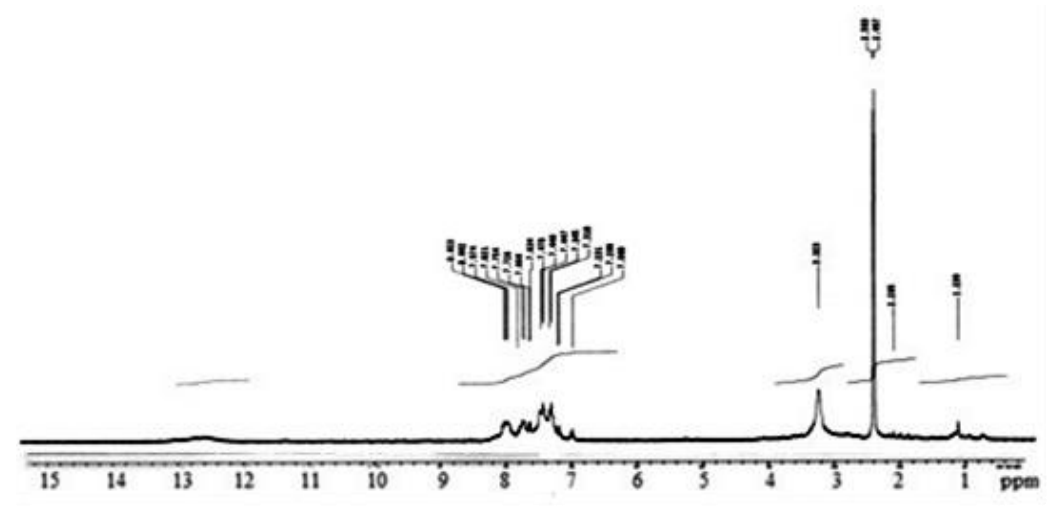

Fig. 2. ${ }^{1}$ H-NMR spectra of N-(benzothiazole-2-yl) maleimide (BTM) monomer.

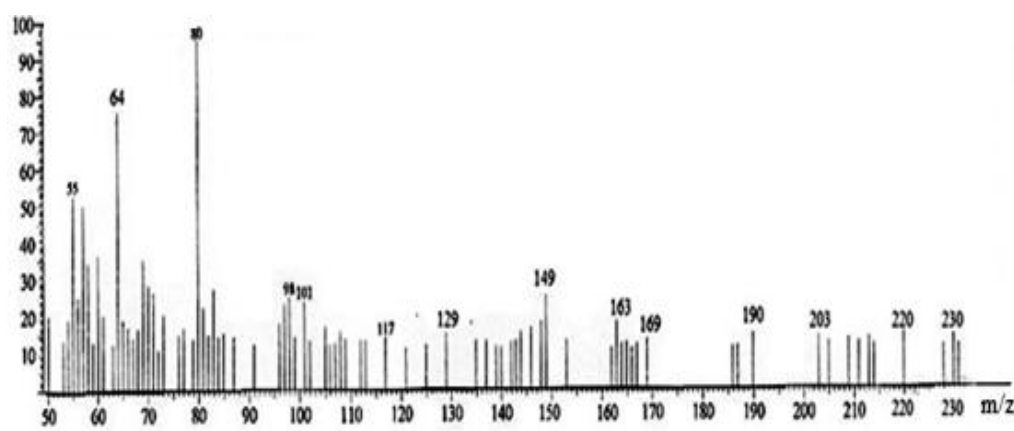

Fig. 3. Mass spectra of N-(benzothiazole-2-yl) maleimide (BTM) monomer.

Egypt. J. Chem. 56, No.4 (2013) 
TABLE 2. Polymerization recipe for various formulations at $80^{\circ} \mathrm{C}$.

\begin{tabular}{|l|c|c|c|c|c|}
\hline Ingredient & $\mathbf{E}_{\mathbf{0}}$ & $\mathbf{E}_{\mathbf{1}}$ & $\mathbf{E}_{\mathbf{2}}$ & $\mathbf{E}_{\mathbf{3}}$ & $\mathbf{E}_{\mathbf{4}}$ \\
\hline Reaction vessel charge & & & & & \\
\hline Deionized water(g) & 14.85 & 14.85 & 14.85 & 14.85 & 14.85 \\
\hline Protective colloid (PVA) (g) & 0.15 & 0.15 & 0.15 & 0.15 & 0.15 \\
\hline Ammonium persulfate (g) & 0.096 & 0.096 & 0.096 & 0.096 & 0.096 \\
\hline Ammonium hydroxide(25\%)(g) & 0.5 & 0.5 & 0.5 & 0.5 & 0.5 \\
\hline Pre-emulsion & & & & & \\
\hline Ethyl acrylate (EA) (g) & 24 & 24 & 24 & 24 & 24 \\
\hline Methyl methacrylate (MMA) (g) & 1 & 1 & 1 & 1 & 1 \\
\hline Styrene (St) (g) & 23 & 22.52 & 22.04 & 21.56 & 21.08 \\
\hline $\begin{array}{l}\text { N-(benzothiazole-2-yl) maleimide (BTM) } \\
\text { (g) }\end{array}$ & 0 & 0.48 & 0.96 & 1.44 & 1.92 \\
\hline $\begin{array}{l}\text { Sodium lauryl sulfate (SLS) -emulsifier } \\
\text { (g) }\end{array}$ & 0.8 & 0.8 & 0.8 & 0.8 & 0.8 \\
\hline Deionized water (g) & 29.7 & 29.7 & 29.7 & 29.7 & 29.7 \\
\hline Protective colloid (PVA) (g) & 0.3 & 0.3 & 0.3 & 0.3 & 0.3 \\
\hline Initiator solution & & & & & \\
\hline Deionized water (g) & 5.22 & 5.22 & 5.22 & 5.22 & 5.22 \\
\hline Ammonium persulfate(g) & 0.384 & 0.384 & 0.384 & 0.384 & 0.384 \\
\hline
\end{tabular}

Solubility studies and spectral analysis of new acrylate copolymers based on $N$ (benzothiazole-2-yl) maleimide (BTM)

The polymers basically have low solubility, or no solubility, in organic solvents. The prepared acrylate polymers, which have been synthesized with or without BTM, are no exception. They become soluble by heating in DMF, THF and toluene, but are insoluble in acetone, Dioxane, DMSO, chloroform, n-hexane, methanol and ethanol. The characterization of these polymers is very difficult due to their limited solubility. The key peaks of the IR spectra of the prepared polymers are shown in Fig.4. It is shown from the figure that specific bands at $1708 \mathrm{~cm}^{-1}$ and $1715 \mathrm{~cm}^{-1}$ can be attributed to $\mathrm{C}=\mathrm{O}$ stretching vibration of the ester groups. The bands at $2925 \mathrm{~cm}^{-1}$ and $2977 \mathrm{~cm}^{-1}$ are assigned to aliphatic $\mathrm{C}-\mathrm{H}$ stretching vibration of methyl and methylene groups. The $\mathrm{C}-\mathrm{H}$ stretching vibration of the aromatic ring is assigned to a band around $3025 \mathrm{~cm}^{-1}$. The bands at $1450 \mathrm{~cm}^{-1}$ and $1495 \mathrm{~cm}^{-1}$ are assigned to an aromatic ring. The absorption around $1377 \mathrm{~cm}^{-1}$ may be traced to the in plane bending vibrations of methyl or methylene groups. The band at $1150 \mathrm{~cm}^{-1}$ may be attributed to the $\mathrm{C}-\mathrm{O}$ stretching vibration of the ester group. Characteristic bands around $1600 \mathrm{~cm}^{-1}$ and $1449 \mathrm{~cm}^{-1}$ are attributed to $\mathrm{C}=\mathrm{N}$ and $\mathrm{C}-\mathrm{N}$ stretching vibrations, respectively. These absorption bands indicate that the BTM monomer is involved in the polymerization process. The absorption around $1380 \mathrm{~cm}^{-1}$ may be traced to the in plane bending vibrations of methyl or methylene groups. The $\mathrm{C}-\mathrm{O}$ stretching vibration of ester groups is indicated by a band at $1160 \mathrm{~cm}^{-1}$. The main evidence for the copolymer formation is certainly the disappearance of the characteristic band of vinyl groups at 1680 $\mathrm{cm}^{-1}$. 


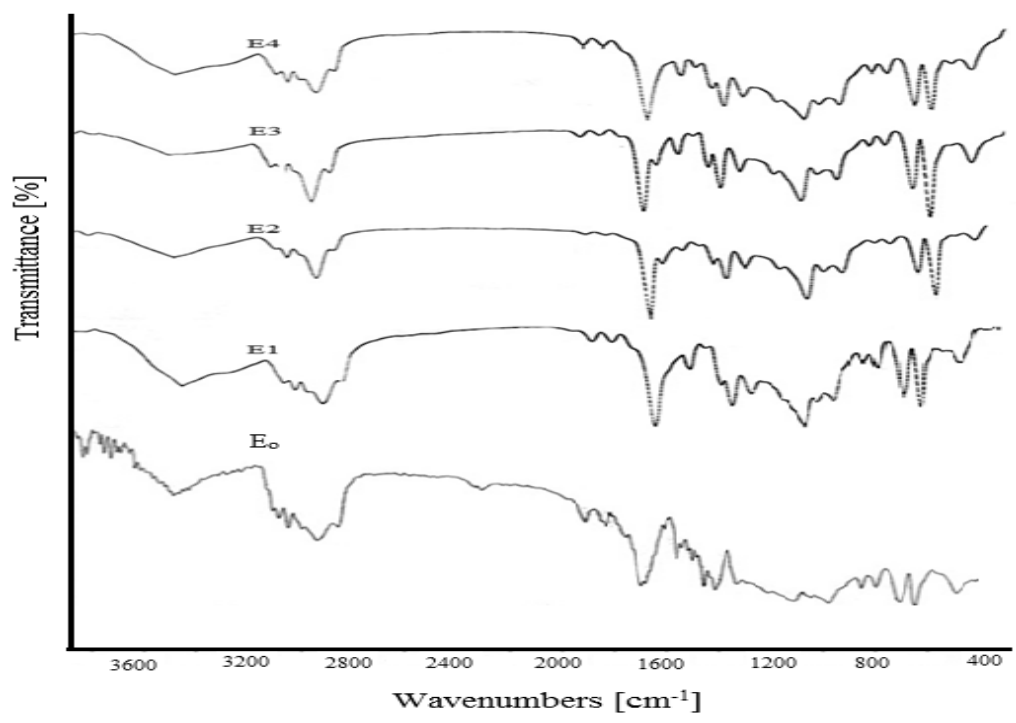

Fig. 4. IR spectra of new acrylate copolymers formulations.

Average molecular weights of new acrylate copolymers based on $\mathrm{N}$ (benzothiazole-2-yl) maleimide (BTM)

The average molecular weight of the prepared polymers $\left(E_{0}-E_{4}\right)$ was determined by gel permeation chromatography (GPC). The results obtained are shown in Table 3. It is clearly seen from the data shown in the table that the average molecular weight $\left(\mathrm{M}_{\mathrm{w}}\right)$ decreases as the BTM content increases. It was shown also from the polydispersity index $\left(M_{w} / M_{n}\right)$, listed in Table, 3 that the polymers are polydisperse. It is well known from the literature that the theoretical values of the polydispersity indexes for polymers, produced by radical combination and disproportionation, are 1.5 and 2.0 , respectively ${ }^{(14)}$. The results shown in Table 3 reveal that the chain termination takes place predominantly by disproportionation, rather than coupling, during the polymerization of BTM monomer with St, MMA and EA. The effect of the BTM concentration on monomer conversion is shown in Fig. 5. It can be observed that the monomer conversion decreases with increasing amounts of BTM. This is likely due to the stability of the $\pi$ bond of malimide moiety.

TABLE 3. Average molecular weights of new acrylate polymers determined by GPC.

\begin{tabular}{|c|c|c|c|c|c|c|}
\hline Polymer & $\mathbf{M}_{\mathbf{n}}$ & $\mathbf{M}_{\mathbf{w}}$ & $\mathbf{M}_{\mathbf{z}}$ & $\begin{array}{c}\text { Polydipersity } \\
\left(\mathbf{M}_{\mathbf{w}} / \mathbf{M}_{\mathbf{n}}\right)\end{array}$ & $\begin{array}{c}\text { Conversion } \\
(\mathbf{\%})\end{array}$ & $\begin{array}{c}\text { Solid content } \\
(\mathbf{\%})\end{array}$ \\
\hline $\mathrm{E}_{0}$ & 98505 & 156648 & 229517 & 1.590 & 78.33 & 37.6 \\
\hline $\mathrm{E}_{1}$ & 67032 & 231347 & 413283 & 3.451 & 65.35 & 31.37 \\
\hline $\mathrm{E}_{2}$ & 49037 & 159184 & 381834 & 3.246 & 53.56 & 25.71 \\
\hline $\mathrm{E}_{3}$ & 48757 & 207598 & 511137 & 4.258 & 32 & 15.36 \\
\hline $\mathrm{E}_{4}$ & 35724 & 152335 & 352015 & 4.264 & 44.9 & 21.56 \\
\hline
\end{tabular}

Egypt. J. Chem. 56, No.4 (2013) 


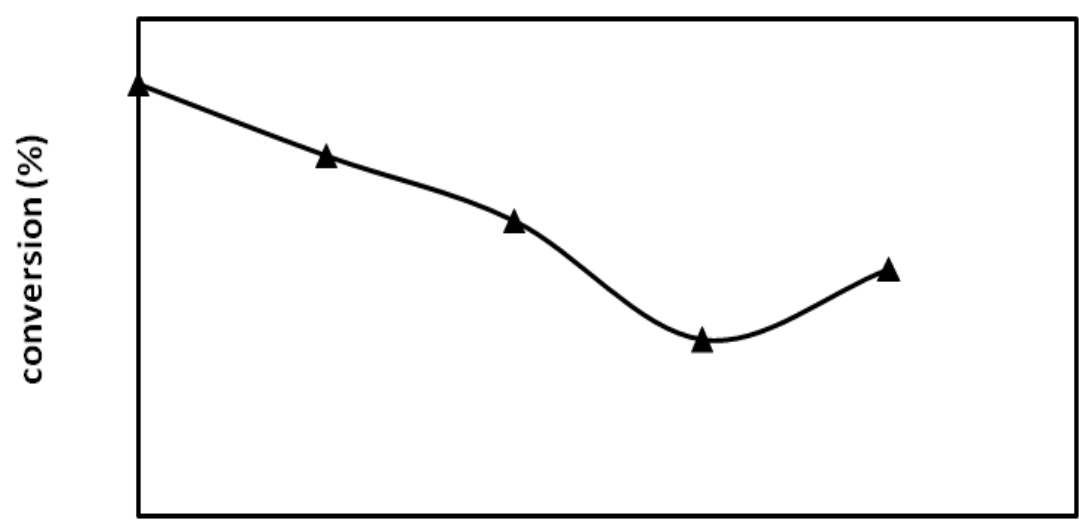

$\%$ wt BTM

Fig. 5. Effect of BTM monomer concentration on conversion.

Thermal gravimetric analysis (TGA) \& Differential scanning calorimetry (DSC)

The results obtained from the TGA work are shown in Table 4 and Fig. 6-10. It is observed from the data in Table 4 and the figures that as the temperature increases, various components of the sample are decomposed and the weight percentage of each resulting mass decreased. The results obtained from the DSC test are shown in Table 5 and Fig. 11. It is shown from the data in Table 5 and Fig. 11 that the control formulation $\mathrm{E}_{0}$ [without BTM monomer] undergoes single step decomposition in the temperature range $345-435{ }^{\circ} \mathrm{C}$, with one DTG peak at $409{ }^{\circ} \mathrm{C}$. This observation is supported by an exothermic peak at $411.69{ }^{\circ} \mathrm{C}$. Also, all the polymer formulations $\left(\mathrm{E}_{1}-\mathrm{E}_{4}\right)$ containing $\mathrm{BTM}$ monomer, undergo single step decomposition over the temperature range from 345 to $436^{\circ} \mathrm{C}$. It was observed also that the synthesized polymers were stable up to $350 \pm 5^{\circ} \mathrm{C}$ and the thermal stability does not depend on the BTM content in the polymers, i.e. it may increase or decrease randomly with decrease in BTM content. The data obtained from the DSC curves were in good agreement with that obtained from the TGA thermograms.

TABLE 4. TGA data of the synthesized polymers.

\begin{tabular}{|c|c|c|c|c|c|c|c|c|c|c|}
\hline \multirow{2}{*}{ Polymer } & \multicolumn{5}{|c|}{$\begin{array}{c}\% \mathrm{Wt} \text { loss at various temperature } \\
\left({ }^{\circ} \mathrm{C}\right)\end{array}$} & \multirow{2}{*}{$\begin{array}{c}\text { Decomposition } \\
\text { Temp. }\left({ }^{\circ} \mathrm{C}\right)\end{array}$} & \multirow{2}{*}{$\begin{array}{l}\mathrm{T}_{15} \\
\left({ }^{\circ} \mathrm{C}\right)\end{array}$} & \multirow{2}{*}{$\begin{array}{l}\mathbf{T}_{50} \\
\left({ }^{\circ} \mathbf{C}\right)\end{array}$} & \multirow{2}{*}{$\begin{array}{c}\mathbf{T}_{\mathbf{9 0}} \\
\left({ }^{\circ} \mathbf{C}\right)\end{array}$} & \multirow{2}{*}{$\begin{array}{l}\mathbf{T}_{\text {Max }} \\
\left({ }^{\circ} \mathbf{C}\right)\end{array}$} \\
\hline & 200 & 300 & 400 & 500 & 600 & & & & & \\
\hline $\mathrm{E}_{0}$ & 2.58 & 5.68 & 37.15 & 93.81 & 94.34 & $345-435$ & 383 & 405 & 423 & 409 \\
\hline $\mathrm{E}_{1}$ & 4.03 & 6.86 & 41.78 & 97.43 & 98.02 & $356-426.41$ & 382 & 403 & 419 & 405 \\
\hline $\mathrm{E}_{2}$ & 4.74 & 7.96 & 44.12 & - & - & 426.41 & 379 & 402 & 416 & 406 \\
\hline $\mathrm{E}_{3}$ & 2.98 & 5.45 & 40.09 & 96.53 & 97.09 & $352-434.84$ & 382 & 404 & 426 & 406 \\
\hline $\mathrm{E}_{4}$ & 3.20 & 7.65 & 46.37 & - & - & $345-435.90$ & 374 & 401 & 422 & 405 \\
\hline
\end{tabular}


TABLE 5. DSC data of the synthesized copolymers.

\begin{tabular}{|c|c|c|c|}
\hline \multirow{2}{*}{ Polymer } & \multicolumn{3}{|c|}{ DSC decomposition temperature $\left({ }^{\mathbf{0}} \mathbf{C}\right.$} \\
\cline { 2 - 4 } & Initial temp. $\left({ }^{\mathbf{0}} \mathbf{C}\right)$ & Peak temp. $\left({ }^{\mathbf{}} \mathbf{C}\right)$ & Final temp. $\left({ }^{\mathbf{0}} \mathbf{C}\right)$ \\
\hline $\mathrm{E}_{0}$ & 362.96 & 411.69 & 437 \\
\hline $\mathrm{E}_{1}$ & 364.99 & 408.9 & 434 \\
\hline $\mathrm{E}_{2}$ & 365.29 & 409.81 & 436 \\
\hline $\mathrm{E}_{3}$ & 367.88 & 409.11 & 444 \\
\hline $\mathrm{E}_{4}$ & 368.44 & 406.51 & 444 \\
\hline
\end{tabular}

\section{Kinetic analysis of thermal degradation}

Thermal degradation kinetic parameters were determined for the acrylate polymer samples from the TGA curves using Broido's (BR), Coats-Redfern (C$\mathrm{R})$ and Horowitz-Metzger (H-M) methods which provide overall kinetic data.

The mathematical expression for Broido's (BR) method is as follows;

$$
\log [-\log (1-\infty)]=-\frac{E_{\alpha}}{2.303 R T}+\log \left[\frac{A R T_{s}^{2}}{\beta E_{\alpha}}\right]
$$

where $\alpha$ is the fraction decomposed at time $\mathrm{t}$ and is given by $\propto=\frac{w_{i}-w_{t}}{w_{i}-w_{f}}$ ( $w_{\mathrm{i}}$ is the mass at the beginning of the decomposition step, $\mathrm{w}_{\mathrm{t}}$ is the mass at time $\mathrm{t}_{\mathrm{f}} \mathrm{w}_{\mathrm{f}}$ is the mass at the end of the decomposition step), where (1- $\alpha)$ is the fraction of the number of initial molecules not yet decomposed, $\mathrm{T}$ is the temperature in Kelvin and $\mathrm{R}$ is the gas constant. $\beta$ is the heating rate and $\mathrm{A}$ is the frequency factor. In this method a straight line should be observed between $\log \{-\log (1-\alpha)\}$ and 1/T with a slope of - $\left(\mathrm{E}_{\mathrm{a}} / 2.303 \mathrm{R}\right)$.

Coats-Redfern (C-R) relation used to evaluate the degradation kinetic is;

$$
\log \left[\frac{-\log (1-\propto)}{T^{2}}\right]=\log \left[\frac{A R}{\beta E_{\alpha}}\right]-\frac{E_{\alpha}}{2.303 R T}
$$

A Plot of $\log \left\{-\log (1-\alpha) / T^{2}\right\}$ versus $1 / T$ gives straight lines where $E_{a}$ and A (Arrhenius pre-exponential factor) were calculated from the slope and the intercept, respectively.

Horowitz-Metzger (H-M) relation used to evaluate the degradation kinetic is;

$$
\log [-\log (1-\propto)]=\frac{\theta E_{\alpha}}{2.303 R T_{s}^{2}} \ldots \ldots \ldots \ldots \ldots \ldots
$$

where $\theta=T-T_{s}, T$ is the temperature corresponding to weight loss; $\mathrm{w}_{\mathrm{t}} . \mathrm{T}_{\mathrm{s}}$ is the temperature at maximum degradation rate. Plot of $\log \{-\log (1-\alpha)\}$ versus $\theta$ should gives a straight line whose slope is $\mathrm{E}_{\mathrm{a}} / 2.303 \mathrm{R} T_{s}{ }^{2}$.

Egypt. J. Chem. 56, No.4 (2013) 


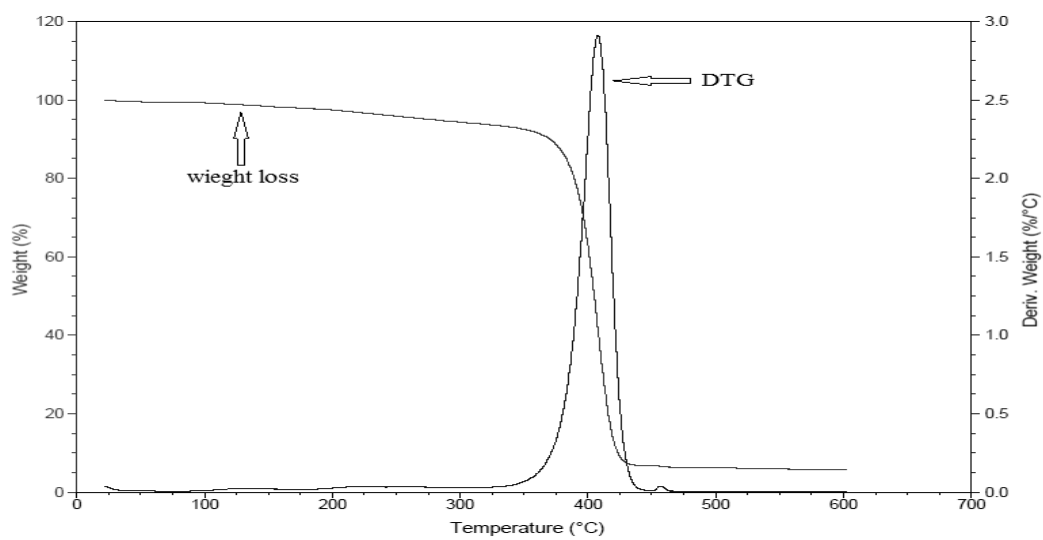

Fig. 6. TGA for formulation $E_{0}$.

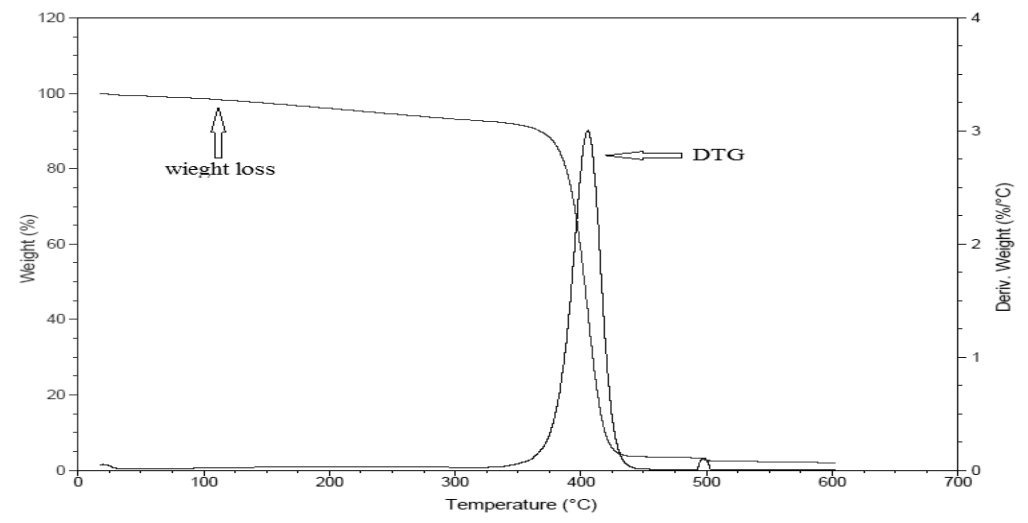

Fig. 7. TGA for formulation $E_{1}$.

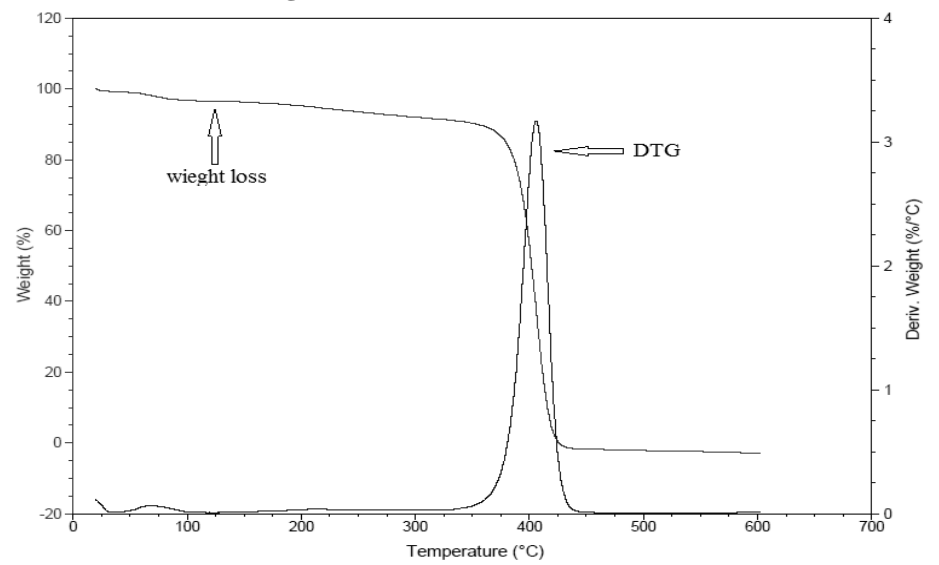

Fig. 8. TGA for formulation $\mathbf{E}_{\mathbf{2}}$.

Egypt. J. Chem. 56, No.4 (2013) 


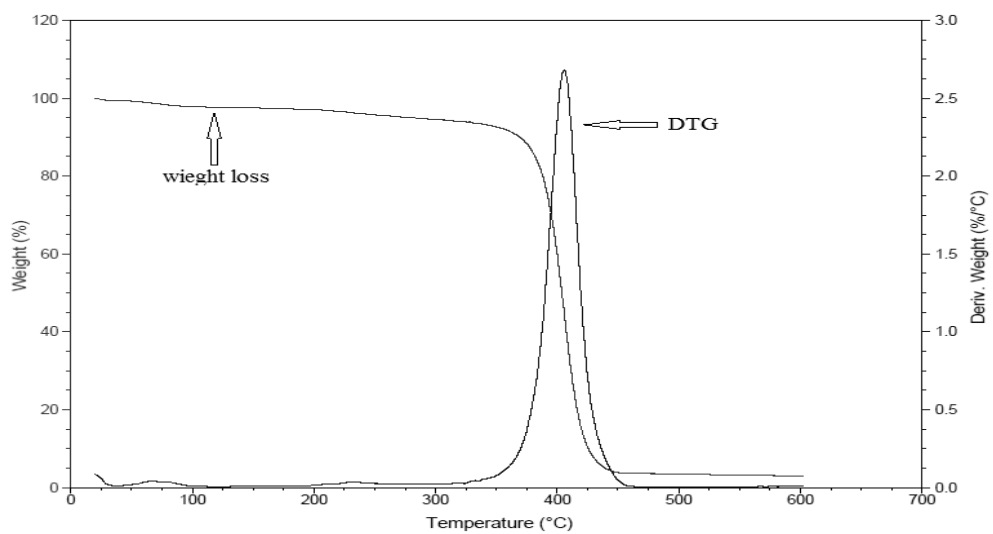

Fig. 9. TGA for formulation of $E_{3}$.

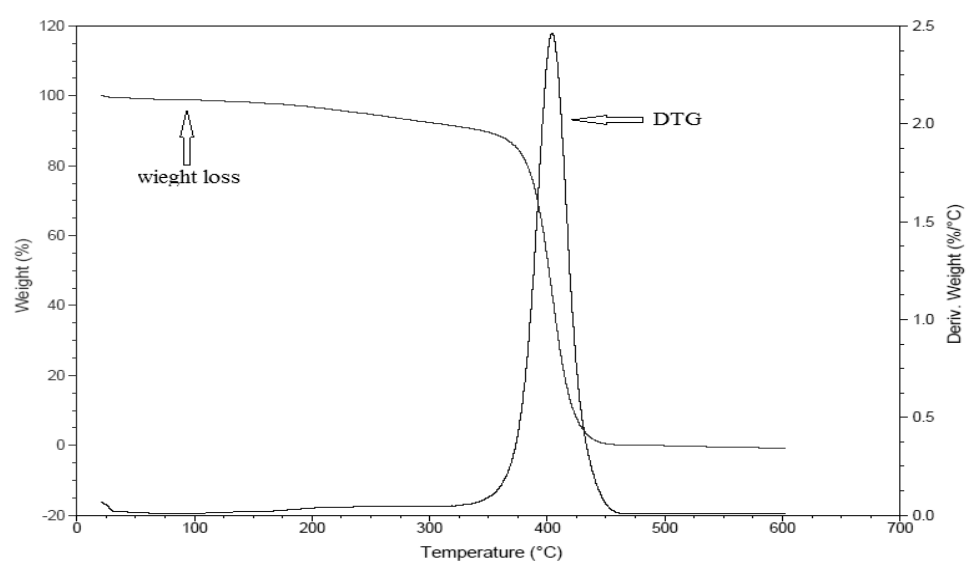

Fig.10. TGA for formulation $E_{4}$.

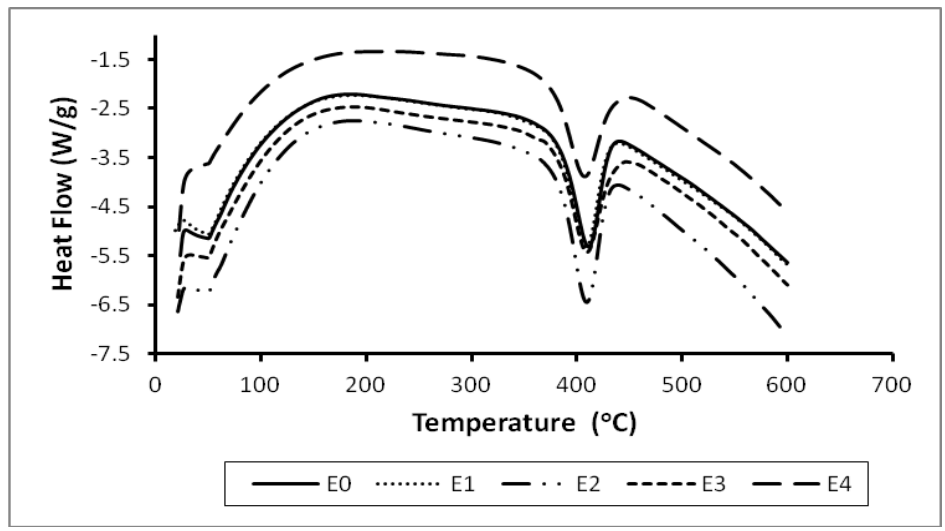

Fig.11. DSC curves for copolymers $\left(\mathbf{E}_{0 .} \mathbf{E}_{4}\right)$.

Egypt. J. Chem. 56, No.4 (2013) 
Representative plots of $\log \{-\log (1-\alpha)\}$ versus $1 / \mathrm{T}(\mathrm{BR}), \log \{-\log (1-\alpha) /$ $\left.\mathrm{T}^{2}\right\}$ versus $1 / \mathrm{T}(\mathrm{C}-\mathrm{R})$ and $\log \{-\log (1-\alpha)\}$ versus $\theta(\mathrm{H}-\mathrm{M})$ for polymers are shown in Fig. 12, 13 and 14, respectively. The regression analysis gives the slopes, constants and $\mathrm{R}^{2}$ for the degradation process. The linear plot, with a concurrency value $\left(\mathrm{R}^{2}\right)$ closer to one, was chosen for both methods. The activation energy (Ea), Arrhenius pre-exponential factor (A) and correlation coefficient $\left(\mathrm{R}^{2}\right)$ for the thermal degradation process and for each method, are tabulated in Table 6 . The correlation coefficient $\left(\mathrm{R}^{2}\right)$ of the linearization plots of the thermal decomposition steps, using the three calculation methods, were found to lie in the range (0.9803-0.9992) showing a good fit with the linear function. The activation energy $\left(E_{a}\right)$ values lie in the range $295.1-373.1 \mathrm{~kJ} / \mathrm{mol}$ for Broido's method, 284.1-362.2 kJ/mol for Coats-Redfern method and $310-394.8$ $\mathrm{kJ} / \mathrm{mol}$ for Horowitz-Metzger method. Variation of (Ea) values calculated by the three mathematical methods, with \%wt of BTM monomer in the acrylate polymer, is shown in Fig.15. It was observed that the difference in the values of the activation energies, due to the three calculation methods used for the same sample, are relatively small. The data indicates a tendency for higher activation energies when calculating with the HM method.

TABLE 6. Kinetic parameters of new acrylate polymers by Broido's (BR), CoatsRedfern (CR) and Horowitz-Metzger (HM) methods.

\begin{tabular}{|c|c|c|c|c|c|c|c|c|c|}
\hline \multirow{2}{*}{ Polymer } & \multicolumn{3}{|c|}{ BR } & \multicolumn{3}{|c|}{$\mathbf{C}-\mathbf{R}$} & \multicolumn{3}{|c|}{ H-M } \\
\cline { 2 - 10 } & $\begin{array}{c}\mathbf{E}_{\mathbf{a}} \\
\mathbf{K J} / \mathbf{m o l}) \\
\mathbf{4 \pm}\end{array}$ & $\mathbf{R}^{\mathbf{2}}$ & $\begin{array}{c}\mathbf{A} \\
\left(\mathbf{m i n}^{-\mathbf{1}}\right)\end{array}$ & $\begin{array}{c}\mathbf{E}_{\mathbf{a}} \\
(\mathbf{K J} / \mathbf{m o l}) \\
\mathbf{4} \pm\end{array}$ & $\mathbf{R}^{\mathbf{2}}$ & $\begin{array}{c}\mathbf{A} \\
\left(\mathbf{m i n}^{-\mathbf{1}}\right)\end{array}$ & $\begin{array}{c}\mathbf{E}_{\mathbf{a}} \\
(\mathbf{K J} / \mathbf{m o l}) \\
\mathbf{4 \pm}\end{array}$ & $\mathbf{R}^{\mathbf{2}}$ & $\begin{array}{c}\mathbf{A} \\
\left(\mathbf{m i n}^{-\mathbf{1}}\right)\end{array}$ \\
\hline $\mathrm{E}_{0}$ & 354.3 & 0.9896 & $1.3 \times 10^{27}$ & 343.3 & 0.9983 & $1.4 \times 10^{53}$ & 377.6 & 0.9992 & $7.7 \times 10^{28}$ \\
\hline $\mathrm{E}_{1}$ & 368.5 & 0.9852 & $1.7 \times 10^{28}$ & 357.5 & 0.9916 & $4.9 \times 10^{55}$ & 385.7 & 0.9903 & $5 \times 10^{29}$ \\
\hline $\mathrm{E}_{2}$ & 373.1 & 0.9833 & $4.2 \times 10^{28}$ & 362.2 & 0.9918 & $3.9 \times 10^{56}$ & 394.8 & 0.9803 & $2.3 \times 10^{30}$ \\
\hline $\mathrm{E}_{3}$ & 295.1 & 0.9834 & $2.6 \times 10^{22}$ & 284.1 & 0.9902 & $2.6 \times 10^{42}$ & 310 & 0.989 & $5.4 \times 10^{23}$ \\
\hline $\mathrm{E}_{4}$ & 308.6 & 0.9919 & $3.2 \times 10^{23}$ & 297.6 & 0.9864 & $8.1 \times 10^{44}$ & 320.8 & 0.9933 & $4.6 \times 10^{24}$ \\
\hline
\end{tabular}

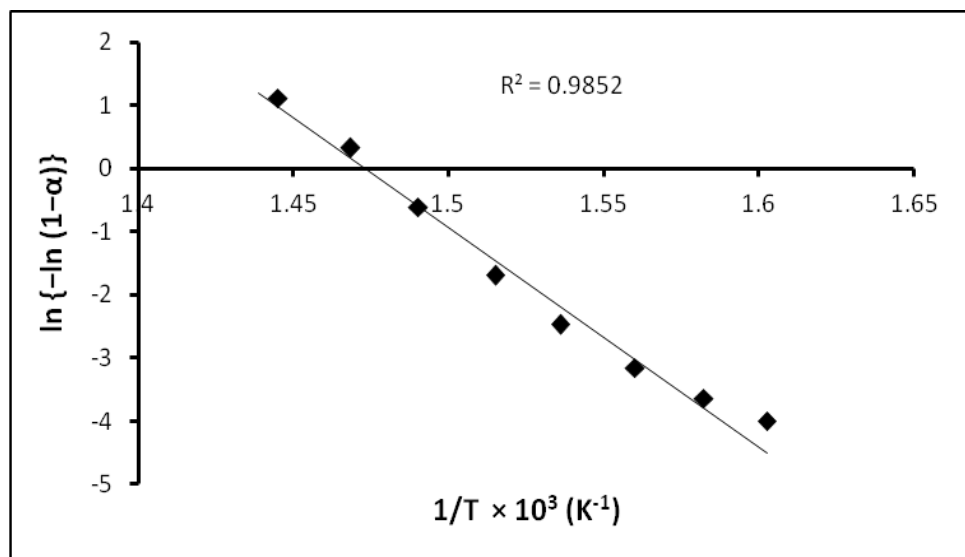

Fig. 12. Kinetic analysis of thermal degradation using Broido's plot method.

Egypt. J. Chem. 56, No.4 (2013) 


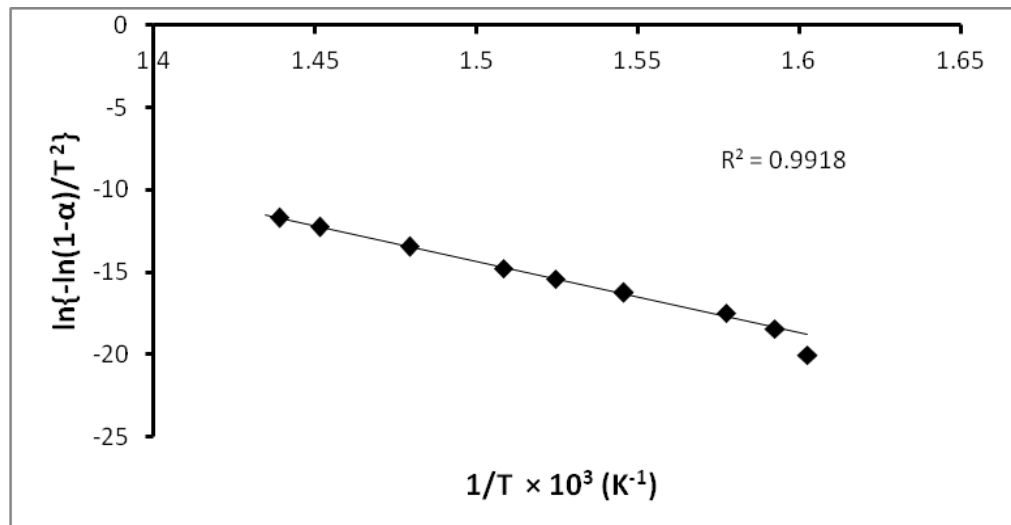

Fig. 13. Kinetic analysis of thermal degradation using Coats-Redfern plot method.

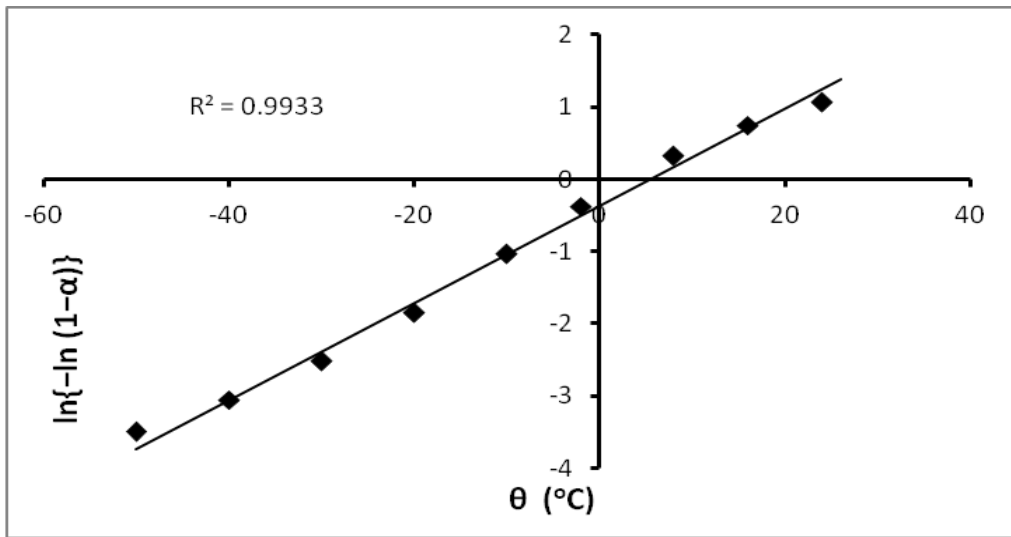

Fig. 14. Kinetic analysis of thermal degradation using Horowitz-Metzger plot method.

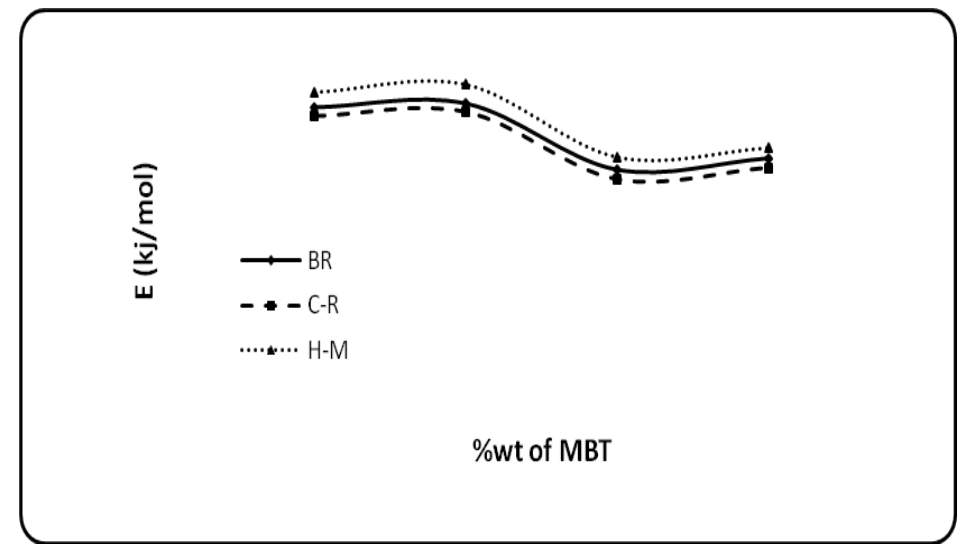

Fig. 15. Variation of activation energy (E) with \%wt of MBT monomer.

Egypt. J. Chem. 56, No.4 (2013) 


\section{Conclusion}

Synthesis and characterization of the new monomer, N-(benzothiazole-2-yl) maleimide (MBT) is reported. Novel acrylate polymers were prepared from different feed compositions of ethylacrylate (EA), methyl-methacrylate (MMA), styrene (St) and BTM by emulsion polymerization in water, using sodium lauryl sulfate as a surfactant and ammonium persulfate as a water-soluble radical initiator. The synthesized monomer and polymers were characterized by spectroscopic methods. Thermal stability of the obtained polymers was reported. Thermo gravimetric curves showed that all polymers undergo single step decomposition. The mechanism of polymer degradation was confirmed by studying kinetic analysis, using Broido, Coats-Redfern and Horowitz-Metzger plot methods.

Acknowledgement: Support of this study by the Egyptian Petroleum Research Institute (EPRI), Cairo, Egypt, is gratefully appreciated.

\section{References}

1. Thanun, M. Pyriadi and Ahmad S. Hamad, Preparation of new copolymers of vinyl acetate and $N$-substituted maleimides. Polymer, 37, 5283-5287 (1996).

2. Yilmaz, F., Cianga, L., Guner, Y., Topppare, L. and Yagci, Y., Synthesis and characterization of alternating copolymers of thiophene-containing N-phenyl maleimide and styrene by photoinduced radical polymerization and their use in electropolymerization. Polymer, 45, 5765-5774 (2004).

3. Jamie Carberry, Jennifer A. Irvin, Daniel, T. Glatzhofer, Kenneth M. Nicholas and Charles J. Neef, High molecular weight copolymers of vinylferrocene and 3 phenyl[5]ferroceno- phane-1,5-dimethylene with various $\mathrm{N}$-substituted maleimides. Reactive and Functional. Polymers, 73, 730-736 (2013).

4. Ahmad, E. E. M. and Luyt, A. S., Effects of organic peroxide and polymer chain structure on morphology and thermal properties of sisal fibre reinforced polyethylene composites. Applied Science and Manufacturing, 43, 703-710 (2012).

5. Jerome Garnier, Pierre-Emmanuel Dufils, Jerome Vinas, Yves Vanderveken, Alex van Herk and Patrick Lacroix-Desmazes, Synthesis of poly(vinylidene chloride)based composite latexes by emulsion polymerization from epoxy functional seeds for improved thermal stability. Polymer Degradation and Stability, 97, 170-177 (2012).

6. Lutz, H., Weitzel, H. P. and Huste, W., Aqueous emulsion polymers polymer Science: A Comprehensive Reference. 10, 479-518 (2012).

7. Saad Alshehri, Amal Al-Fawaz and Tansir Ahamad, Thermal kinetic parameters and evolved gas analysis (TG-FTIR-MS) for thiourea-formaldehyde based polymer metal complexes. Journal of Analytical and Applied Pyrolysis, 101, 215-221(2013). 
8. Hanzhou Liu, Ming Yu, Bo Deng, Linfan Li, Haiqing Jiang and Jingye Li, Preirradiation induced emulsion graft polymerization of acrylonitrile onto polyethylene nonwoven fabric. Radiation Physics and Chemistry, 81, 93-96 (2012).

9. Sinem Kadriye Cekingen, Fehmi Saltan, Yeliz Yildirim and Hakan Akat, A novel HEMA-derived monomer and copolymers containing side-chain thiophene units: Synthesis, characterization and thermal degradation kinetics. Thermochimica Acta, 546, 87-93 (2012).

10. Broido, A., A simple, sensitive graphical method of treating thermogravimetric analysis data. Journal of Polymer Science Part A: Polymer Physics, 27, 1761-1774 (1969).

11. Coats, A. W. and Redfern, J. P., Kinetics parameters from thermogravimetric data Nature, 201, 68 (1964).

12. Horowitz, H. and Metzger, G., A new analysis of thermogravimetric traces. Analytical Chemistry. 35, 1464-1468 (1964).

13. Vijayanand, P. S., Kato, S., Satokawa, S. and Kojima, T., Homopolymer and copolymers of 4-nitro-3- methylphenyl methacrylate with glycidyl methacrylate: Synthesis, characterization, monomer reactivity ratios and thermal properties. European Polymer Journal, 43, 2046-2056 (2007).

14. Teramachi, S., Hasegawa, A., Atasuka, M., Yamashita, A. and Takemoto, N., Molecular weight distribution and correlation between chemical composition and molecular weight of high-conversion copolymer of styrene, methyl methacrylate. Macromolecules, 11, 1206-10 (1978). 
تحضير وتوصيف ودراسة السلوك الحرارى لبوليمرات أكريلات جليدة محتوية على بنزوثايزول-2-يل-ماليميا

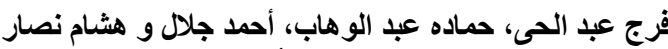

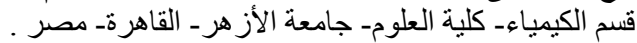

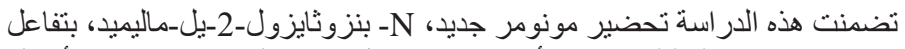

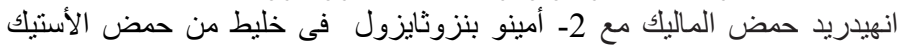

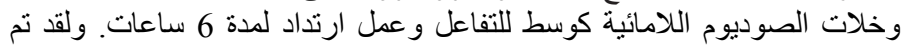

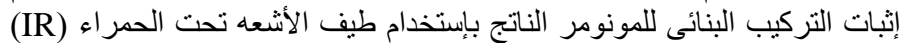

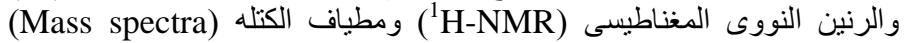

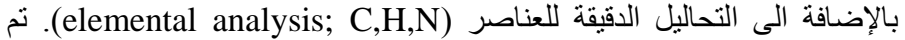

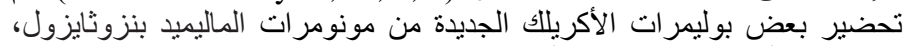

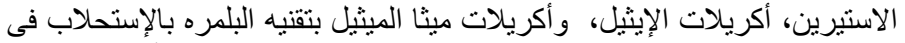

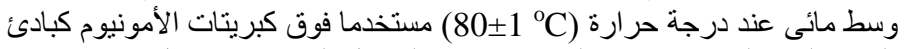

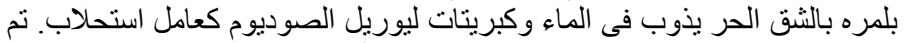

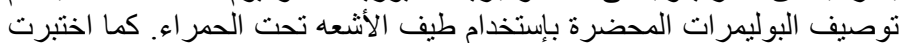

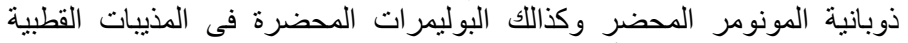

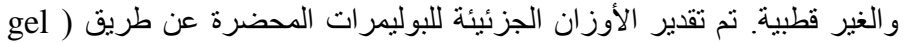
(permeation chromatography

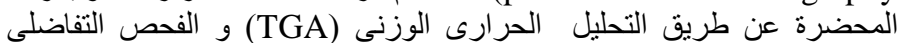

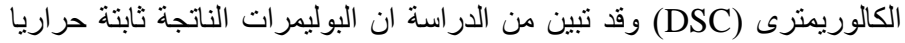

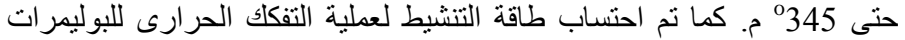

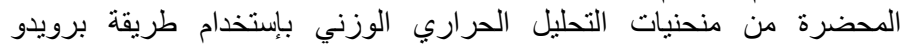

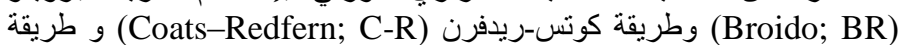

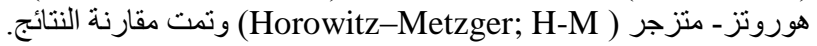

